\title{
Analysis of loss mechanisms in InGaN solar cells using a semi-analytical model
}

Xuanqi Huang, Houqiang Fu, Hong Chen, Zhijian Lu, Ding Ding, and Yuji Zhao

Citation: Journal of Applied Physics 119, 213101 (2016); doi: 10.1063/1.4953006

View online: $\mathrm{http}: / / \mathrm{dx}$.doi.org/10.1063/1.4953006

View Table of Contents: http://aip.scitation.org/toc/jap/119/21

Published by the American Institute of Physics

\section{Articles you may be interested in}

Nonpolar and semipolar InGaN/GaN multiple-quantum-well solar cells with improved carrier collection efficiency Applied Physics Letters 110, 161105 (2017); 10.1063/1.4980139

Role of V-pits in the performance improvement of InGaN solar cells Applied Physics Letters 109, 133507 (2016); 10.1063/1.4963817

Positive temperature coefficient of photovoltaic efficiency in solar cells based on InGaN/GaN MQWs Applied Physics Letters 109, 062104 (2016); 10.1063/1.4960765

Design and characterization of $\mathrm{GaN} / \mathrm{InGaN}$ solar cells Applied Physics Letters 91, 132117 (2007); 10.1063/1.2793180

Dependence of the photovoltaic performance of pseudomorphic InGaN/GaN multiple-quantum-well solar cells on the active region thickness

Applied Physics Letters 108, 161907 (2016); 10.1063/1.4947445

High internal and external quantum efficiency InGaN/GaN solar cells

Applied Physics Letters 98, 021102 (2011); 10.1063/1.3540501

\section{AIP $\left.\right|_{\text {Applied Physics }} ^{\text {Journal }}$}

Save your money for your research.

It's now FREE to publish with us no page, color or publication charges apply.
Publish your research in the

Joumal of Applied Physics

to claim your place in applied

physics history. 


\title{
Analysis of loss mechanisms in InGaN solar cells using a semi-analytical model
}

\author{
Xuanqi Huang, ${ }^{\text {a) }}$ Houqiang Fu, Hong Chen, Zhijian Lu, Ding Ding, and Yuji Zhao ${ }^{\text {b) }}$ \\ School of Electrical, Computer and Energy Engineering, Arizona State University, Tempe, Arizona 85287. \\ USA
}

(Received 24 February 2016; accepted 17 May 2016; published online 1 June 2016)

\begin{abstract}
InGaN semiconductors are promising candidates for high-efficiency next-generation thin film solar cells. In this work, we study the photovoltaic performance of single-junction and two-junction InGaN solar cells using a semi-analytical model. We analyze the major loss mechanisms in InGaN solar cell including transmission loss, thermalization loss, spatial relaxation loss, and recombination loss. We find that transmission loss plays a major role for InGaN solar cells due to the large bandgaps of III-nitride materials. Among the recombination losses, Shockley-Read-Hall recombination loss is the dominant process. Compared to other III-V photovoltaic materials, we discovered that the emittance of InGaN solar cells is strongly impacted by Urbach tail energy. For two- and multi-junction InGaN solar cells, we discover that the current matching condition results in a limited range of top-junction bandgaps. This theoretical work provides detailed guidance for the design of high-performance InGaN solar cells. Published by AIP Publishing. [http://dx.doi.org/10.1063/1.4953006]
\end{abstract}

\section{INTRODUCTION}

Wurtzite (In, Ga, Al)N semiconductors, especially InGaN material systems, demonstrate immense promises for the high efficiency thin film photovoltaic (PV) applications for future generation. ${ }^{1}$ Their unique and intriguing merits include continuously tunable wide band gap from $0.70 \mathrm{eV}$ to $3.4 \mathrm{eV}$, strong absorption coefficient on the order of $10^{5} \mathrm{~cm}^{-1}$, superior radiation resistance under harsh environment, and high saturation velocities and high mobility. ${ }^{2}$ Calculation from the detailed balance model also revealed that in multi-junction (MJ) solar cell device, materials with band gaps higher than $2.4 \mathrm{eV}$ are required to achieve PV efficiencies greater than $50 \%,{ }^{3}$ which is practically and easily feasible for InGaN materials. Other state-of-art modeling on InGaN solar cells also demonstrate great potential for applications of III-nitride solar cells in four-junction solar cell devices as well as in the integration with a non-III-nitride junction in multi-junction devices. ${ }^{4-6}$ However, due to distinct material properties from conventional III-V PV materials, the fundamental PV processes and corresponding loss mechanisms in InGaN solar cells are still not well understood. It is therefore imperative to investigate the major loss mechanism in InGaN solar cells for the design and optimization of high efficiency InGaN solar cells.

In this work, a semi-analytical model for solar cells ${ }^{7}$ is adopted to investigate the optical property, efficiency limits, and loss mechanisms in InGaN PV solar cells. Compared to commercial software such as Silvaco or Crosslight, this model requires less time to calculate and is capable of revealing the intrinsic physical reasons straightforwardly. In the simulation, we also incorporate non-ideal properties such as photon recycling, spontaneous emission coupling, the non-step absorptance, and emittance of junctions and

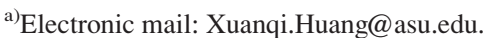

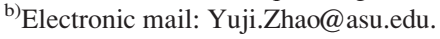

absorption tails below the bandgap. The equations and details of these non-ideal properties can be found in Ref. 7. These factors are all accounted for complicated physical processes in real solar cells. The efficiencies and device performance are calculated for four different solar cell structures, and the loss mechanisms are examined thoroughly to provide basic guidance for the design of InGaN solar cells.

\section{SIMULATION METHODS}

\section{A. Loss mechanisms}

We focus on four major loss mechanisms ${ }^{7,8}$ in InGaN solar cells: (i) transmission losses due to photons transmitting through the device without being absorbed; (ii) thermalization losses resulting from carriers in excited states returning to band edges; (iii) spatial relaxation losses due to carriers losing potential energy while being separated and collected at the contacts; and (iv) recombination losses due to Shockley-Read-Hall (SRH) and Auger recombination. ${ }^{9}$ The expressions and details of losses and extracted power can be referred to Ref. 7. In order to focus on the intrinsic properties of materials and devices, this study do not take into account other losses, for instance, surface recombination, series resistance, and shunt resistance, which are closely related to the device fabrication process. The total current density of a single junction (1J) solar cell is given as

$$
J_{\text {total }}=J_{s c}-J_{\text {rad }}-J_{S R H}-J_{\text {Auger }},
$$

where $J_{s c}$ is the short-circuit current density that is mainly determined by the absorptance of the cell, including belowbandgap absorption; $J_{\text {rad }}, J_{S R H}$, and $J_{\text {Auger }}$ are the radiative, $\mathrm{SRH}$, and Auger recombination current density, respectively.

\section{B. Planar structures}

Figure 1 presents four planar structures with different surface configurations that are simulated in the analysis. 
Structure A and C both have the non-reflective interface between semiconductor and substrate with smooth (structure A)/textured upper surface (structure C), respectively; structure B and D both have $100 \%$ ideal reflective lower interface with smooth (structure B)/textured (structure D) upper surface, respectively. All of these structures are commonly used in InGaN solar cells while more complicated planar structures were explored in Ref. 10. Note that in this work, upper surface corresponds to the front surface facing incident sunlight and lower surface indicates the bottom surface of a semiconductor attaching to the substrate. For InGaN solar cells, structure A is first proposed in Ref. 3 and is widely adopted due to the simple fabrication processes, while structure $\mathrm{C}$ is proven to be more effective to trap light and improve the device performance, both in conventional PIN structure and in quantum well structure. ${ }^{11-14}$ Note that for textured upper surface widely used in InGaN solar cells and light emitting diodes (LEDs), they are applied on the top layers like contacts or anti-reflecting layers. Structure B and $\mathrm{D}$ are investigated for comparison.

\section{Absorptance and emittance}

The AM1.5G solar spectrum is used in the calculation. $\mathrm{In}_{0.15} \mathrm{Ga}_{0.85} \mathrm{~N}$ is employed as the active layer for the study and published material parameters of bandgap energy $E_{g},{ }^{15}$ refractive index $n_{r},{ }^{16}$ and Urbach tail energy $E_{u}=0.050 \mathrm{eV}$ (Ref. 17) are adopted. From statistical ray optics, the analytical equations of the absorptance are derived as follows: ${ }^{7}$

$$
\begin{gathered}
A_{\alpha} \cong 1-e^{-\alpha \cdot d}, \quad \text { for structure } \mathrm{A}, \\
A_{\alpha} \cong 1-e^{-\alpha \cdot 2 d}, \quad \text { for structure } \mathrm{B}, \\
A_{\alpha}=1-t_{\alpha}, \quad \text { for structure } \mathrm{C}, \\
A_{\alpha}=1-\frac{1-t_{\alpha}}{1-\left(1-\frac{1}{n_{r}^{2}}\right) t_{\alpha}}, \quad \text { for structure } \mathrm{D},
\end{gathered}
$$

where $\alpha$ is the absorption coefficient, $d$ is the semiconductor thickness, $n_{r}$ is the refractive index, and $t_{\alpha}$ indicates the fraction of lost photons in a single pass through the slab, with

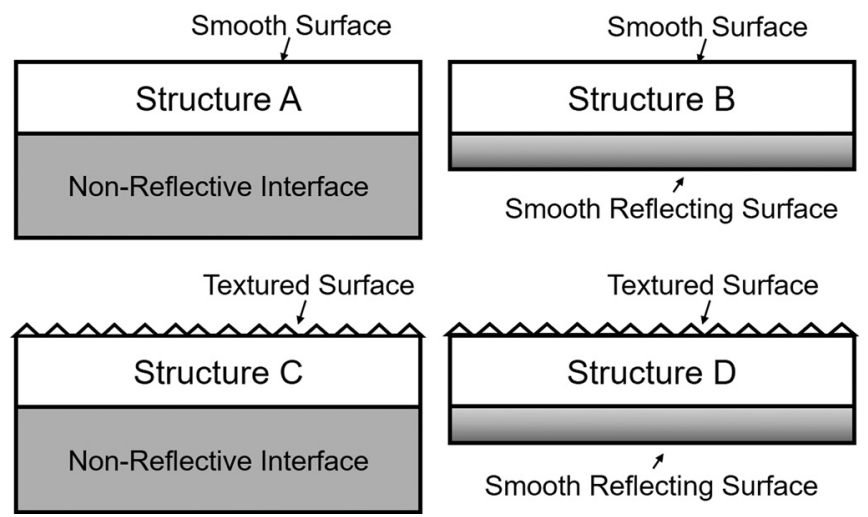

FIG. 1. Schematic diagrams of four planar solar cell structures used in the study.

$$
\begin{aligned}
& t_{\alpha}=\int_{0}^{\pi / 2} e^{-\alpha \cdot d / \cos \theta} 2 \cos \theta \sin \theta d \theta, \quad \text { for structure } \mathrm{C}, \\
& t_{\alpha}=\int_{0}^{\pi / 2} e^{-2 \alpha \cdot d / \cos \theta} 2 \cos \theta \sin \theta d \theta, \quad \text { for structure } \mathrm{D},
\end{aligned}
$$

where $\theta$ is the angle between the scattered light and the surface normal. By assuming the Lambertian scattering, the portion of light distributed in the solid angle $\sin \theta d \theta$ is $2 \cos \theta$, which could also be modified by other scattering functions other than Lambertian scattering.

The upper- and lower-surface emittance is given by

$$
\begin{aligned}
\varepsilon_{\text {upper }}= & 1-n_{r}^{2} \int_{0}^{\pi / 2} e^{-\alpha \cdot d / \cos \theta} 2 \cos \theta \sin \theta d \theta, \quad \text { for structure } \mathrm{A}, \\
\varepsilon_{\text {lower }}= & 1-\int_{0}^{\theta_{c}} e^{-\alpha \cdot d / \cos \theta} 2 \cos \theta \sin \theta d \theta \\
& -\int_{\theta_{c}}^{\pi / 2} e^{-2 \alpha \cdot d / \cos \theta} 2 \cos \theta \sin \theta d \theta, \quad \text { for structure } \mathrm{A},
\end{aligned}
$$

$$
\varepsilon_{\text {upper }}=1-n_{r}^{2} \int_{0}^{\pi / 2} e^{-\alpha \cdot 2 d / \cos \theta} 2 \cos \theta \sin \theta d \theta, \text { for structure } \mathrm{B},
$$

$$
\varepsilon_{\text {lower }}=0, \quad \text { for structure } \mathrm{B} \text { and } \mathrm{D} \text {, }
$$

$$
\varepsilon_{\text {upper }}=A_{\alpha}, \quad \text { for structure } \mathrm{C} \text { and } \mathrm{D},
$$

$\varepsilon_{\text {lower }}=\left(1-t_{\alpha}\right)\left[1+\left(1-\frac{1}{n_{r}^{2}}\right) t_{\alpha}\right], \quad$ for structure $\mathrm{C}$ and $\mathrm{D}$,

where $\theta_{c}$ is the critical angle. When the solar light is incident from all angles, the emittance is equal to absorptance. ${ }^{7}$ In structure $\mathrm{C}$ and $\mathrm{D}$ with same textured surfaces, the upper surface emittance is equivalent to absorptance due to the same absorption and emission path of incident light, while there is zero emittance of lower surface because of the reflecting substrate in structure $\mathrm{C}$ and $\mathrm{D}$. In comparison, for structure A and B with same smooth upper surface, the emittance is somewhat larger than absorptance because of shorter absorption ray path compared to emission.

The energy dependent effective absorptance and emittance are defined as

$$
\begin{gathered}
\overline{A_{\alpha}}=\frac{\int_{0}^{\infty} A_{\alpha} n_{\text {sun }} d h v}{\int_{E_{g}-E_{u}}^{\infty} n_{\text {sun }} d h v}, \\
\bar{\varepsilon}_{\text {upper }}=\frac{\int_{0}^{\infty} \varepsilon_{\text {upper }}\left(n_{v, s p}-n_{v, b b}\right)(h v)^{2} d h v}{\int_{E_{g}-E_{u}}^{\infty}\left(n_{v, s p}-n_{v, b b}(h v)^{2} d h v\right.}, \\
\bar{\varepsilon}_{\text {lower }}=\frac{\int_{0}^{\infty} \varepsilon_{\text {lower }}\left(n_{v, s p}-n_{v, b b}\right)(h v)^{2} d h v}{\int_{E_{g}-E_{u}}^{\infty}\left(n_{v, s p}-n_{v, b b}\right)(h v)^{2} d h v},
\end{gathered}
$$


where $n_{\text {sun }}$ refers to the solar photon flux density per unit area and $n_{v, s p}$ and $n_{v, b b}$ are photon occupation numbers of spontaneous emission and blackbody emission, respectively. Note that this model incorporates below-bandgap tail absorption that is substantial in the practical situation, ${ }^{7}$ which is different from detailed balance model that assumes step-like emittance and absorptance identical to emittance. Figure 2 presents the (a) effective absorptance and (b) emittance under AM1.5G spectrum as a function of physical thickness for four types of structures of $\mathrm{In}_{0.15} \mathrm{Ga}_{0.85} \mathrm{~N}$. For a given device thickness, structure $\mathrm{D}$ has much higher absorptance than structure A, B, and C, due to both textured surface and reflecting substrate, which strongly enhances light trapping and photon recycling processes. The absorptance of structure $\mathrm{B}$ and $\mathrm{C}$ is higher than that of structure $\mathrm{A}$, indicating that both textured surface roughening and reflecting substrate are effective ways to enhance the absorptance, while structure B (reflecting substrate) is slightly better than structure C (textured surface). Moreover, for the same absorptance, structures $\mathrm{A}, \mathrm{B}$, and $\mathrm{C}$ require much larger device thickness due to limited optical path of light scattering and reflecting. Figure 2(b) shows that the emittance of upper surface of structures A, B, and C is much smaller than that of structure D. It is noteworthy that the emittance of lower surfaces of structure $\mathrm{A}$ and $\mathrm{C}$ is higher than that of upper surfaces. This is attributed to the adoption of non-reflective substrates,
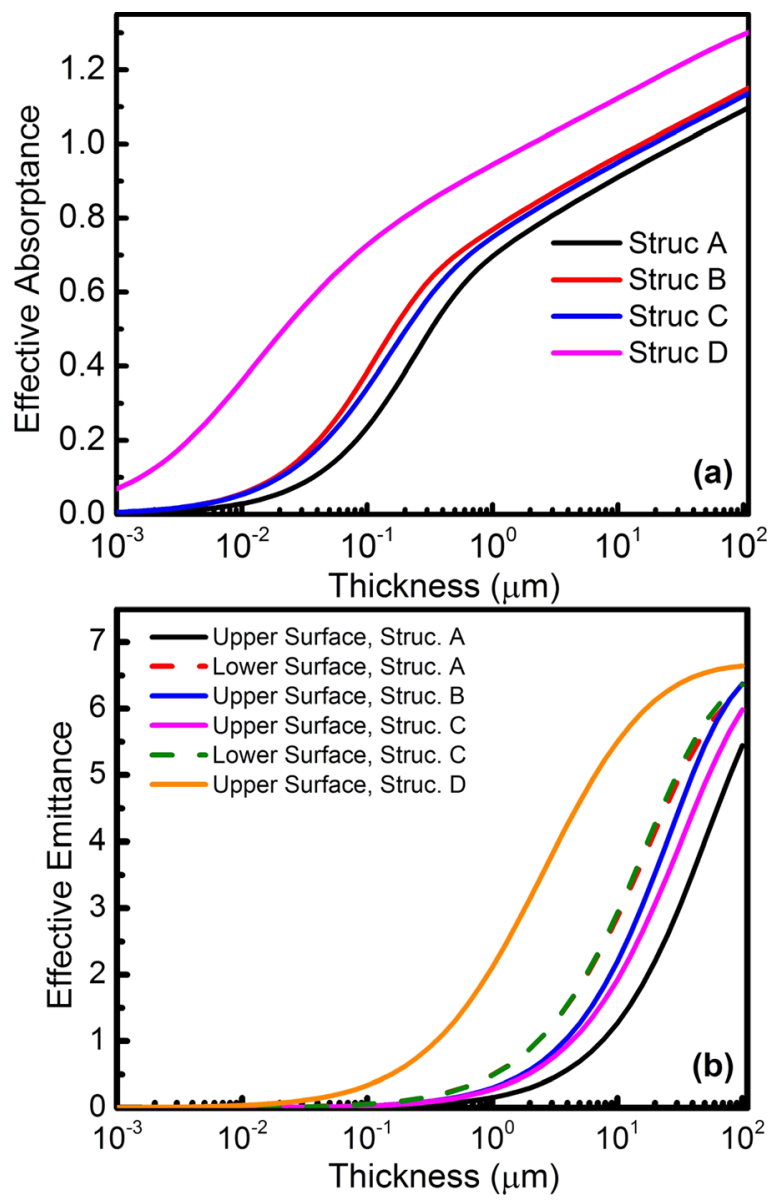

FIG. 2. (a) Effective absorptance vs. physical thickness and (b) effective emittance vs. physical thickness for $\operatorname{In}_{0.15} \mathrm{Ga}_{0.85} \mathrm{~N}$ solar cells in four structures. which gives rise to larger radiation loss in the solar cells. As a result, recent reports on high efficiency InGaN solar cells have been focusing on surface roughening (textured surface) rather than structures with smooth surface and substrate. ${ }^{11-14}$ Other optoelectronic devices have been more inclined to employ pattern sapphire substrates (PSS) to enhance light extraction. ${ }^{18-22}$ Furthermore, despite costly and complicated growth and fabrication process, there have been reports proposing using diffraction grating on the back of the device for InGaN solar cells to enhance the optical absorption, ${ }^{23}$ which combines the textured surface and reflecting substrate. These reports are also consistent with our findings here.

Figure 3 presents effective emittance as a function of effective absorptance, i.e., optical thickness, using different (a) effective bandgaps and (b) Urbach energy $\left(E_{u}\right)$ values as integration boundaries for upper surface in structure $C$. In this work, the effective emittance represents how many Urbach tail states would contribute to radiative recombination. Since Urbach tail energy $\left(E_{u}\right)$ of III-nitrides is normally larger than that of $\mathrm{GaAs}^{24}$ and $\mathrm{Si}^{25}$ it is assumed that the variations of emittance of III-nitrides would be much more pronounced than those of GaAs and Si. Therefore, it is imperative to study different effective band gaps for integration boundaries to investigate the impacts on optical properties
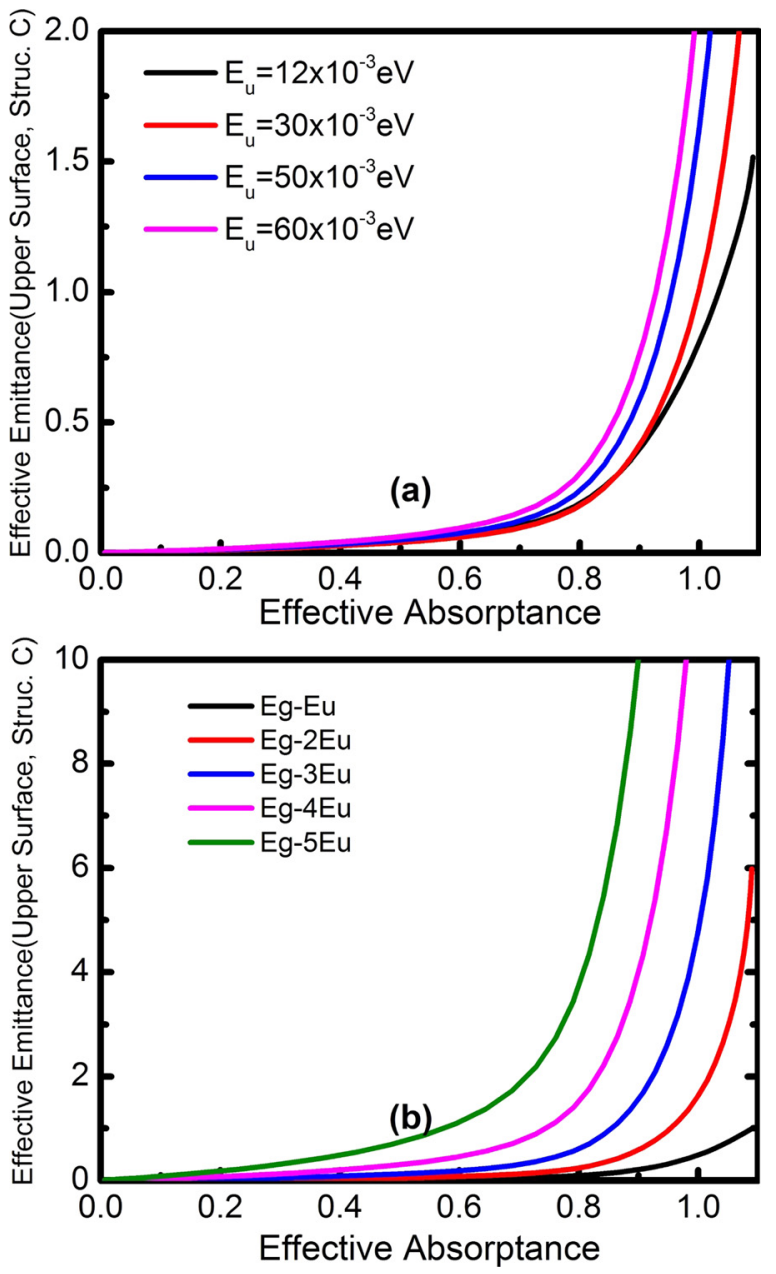

FIG. 3. Effective emittance vs. optical thickness using different (a) effective bandgaps and (b) Urbach energy values as integration boundaries, both for upper surface in structure $\mathrm{C}$. 
and device performance of InGaN solar cells. In the calculation, different effective bandgaps and Urbach energy values have been applied, with integration boundary of $E_{g}-E_{u}$ and $E_{u}=0.050 \mathrm{eV}$ remaining the same, respectively. In Fig. 3(a), the effective emittance of upper surface maintains almost the same before effective absorptance of 0.8 . Afterwards, the effective emittance gradually increases as Urbach tail energy $\left(E_{u}\right)$ goes up. This trend suggests that within certain optical thickness, the value of $E_{u}$ has little influence on the effective emittance. Meanwhile in Fig. 3(b), similar trends are also observed. As effective bandgap goes down, namely, more tail states contribute to radiative recombination, the effective emittance exceeds one and rises dramatically, which could be attributed to the facts that the effective band gap approaches the optimal bandgap of a single junction (1J) solar cell of about $1.4 \mathrm{eV}$ (Ref. 26) and much more emission would be generated than in an ideal semiconductor with band edge at $E_{g}-E_{u}$. It is noticeable that $E_{u}$ is easily affected by extrinsic factors, for instance, the material quality of active layers, defect states, doping density, local stress, ${ }^{27,28}$ and device temperatures under operation, ${ }^{29}$ which indicates that it would change under particular circumstances, even as high as $60 \mathrm{meV}{ }^{17}$

\section{ANALYSIS OF LOSS MECHANISMS IN SINGLE JUNCTION SOLAR CELL}

In this section, we study the PV performance and loss mechanisms in single junction (1J) InGaN solar cells. Instead of physical thickness, the effective absorptance, i.e., the optical thickness, is explored in this part. The SRH recombination current densities per unit length $\left(J_{A} / d\right)$ and Auger recombination current density per unit length $\left(J_{C} / d\right)$ are calculated based on Ref. 9. Figure 4(a) presents the energy conversion efficiency as a function of absorptance for single junction $\mathrm{In}_{0.15} \mathrm{Ga}_{0.85} \mathrm{~N}$ solar cells in structure $\mathrm{C}$ with various $\mathrm{SRH}$ recombination current densities per unit length $\left(J_{A} / d\right)$. An energy conversion efficiency of $7.35 \%$ is obtained for typical reported material quality $\left(J_{A} / d=1000 \mathrm{~A} \mathrm{~cm}^{-2} \mu \mathrm{m}^{-1}\right)$, while the peak efficiency of $8.81 \%$ can be achieved for ideal materials $\left(J_{A} / d=1 \mathrm{~A} \mathrm{~cm}^{-2} \mu \mathrm{m}^{-1}\right)$. Therefore, improving InGaN quality offers an efficient method to increase the solar cell efficiency. In Fig. 4(b), the losses and efficiency distribution were extracted for single junction $\operatorname{In}_{0.15} \mathrm{Ga}_{0.85} \mathrm{~N}$ solar cells with structure $\mathrm{C}$ under $\mathrm{AM} 1.5 \mathrm{G}$ one sun condition. Apparently, transmission loss dominates among all loss mechanisms due to large bandgap energy of III-nitrides than other III-V materials. The thermalization and spatial relaxation loss both rise with increasing effective absorptance due to larger portion of absorbed photons at larger thickness. It is noteworthy that the SRH loss accounts for most of the total recombination-related loss mechanisms, even though there are radiative loss generated from the loss of photon energies larger than bandgap (no reflecting surface employed in structure C) and Auger recombination loss owing to fairly large Auger recombination current density.

Figure 5(a) demonstrates energy conversion efficiency as a function of SRH recombination current densities per unit length $\left(J_{A} / d\right)$ for four structures with typical Auger
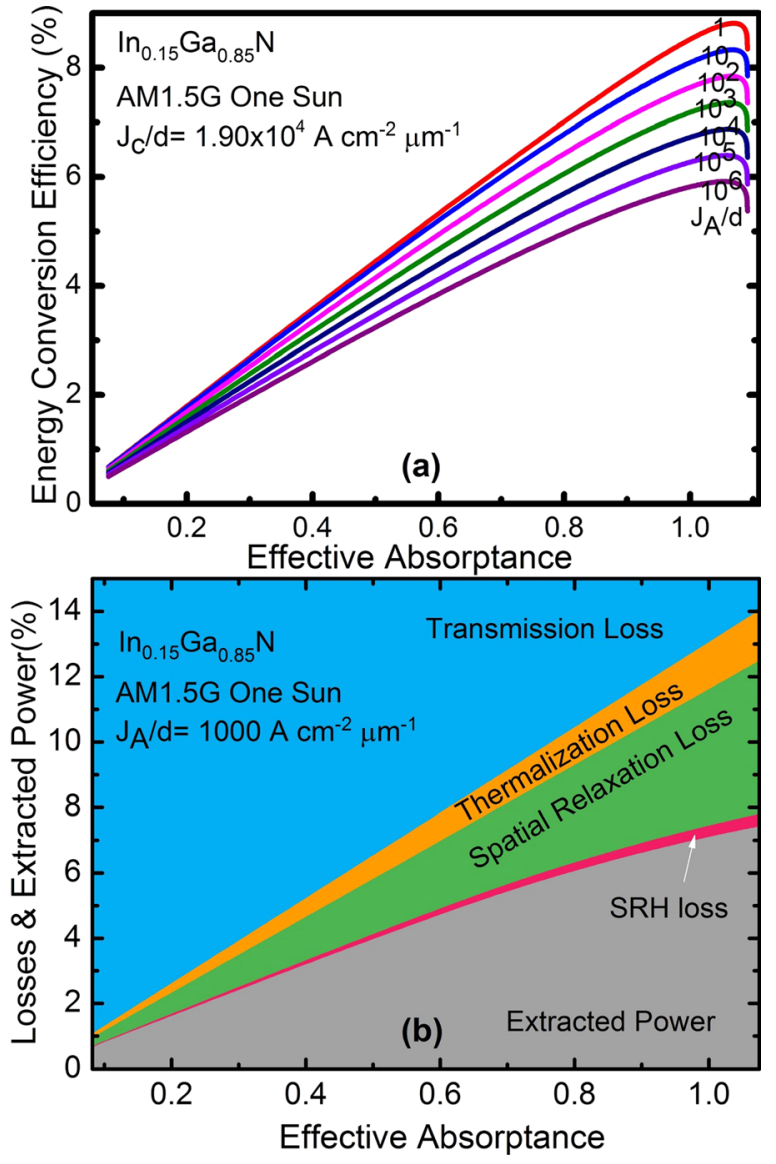

FIG. 4. (a) Energy conversion efficiency vs. effective absorptance (i.e., optical thickness) for $1 \mathrm{~J} \mathrm{In}_{0.15} \mathrm{Ga}_{0.85} \mathrm{~N}$ solar cells in structure $\mathrm{C}$ with particular SRH recombination current densities per unit length, $J_{A} / d$. (b) Losses and extracted power vs. absorptance for single junction $\operatorname{In}_{0.15} \mathrm{Ga}_{0.85} \mathrm{~N}$ solar cell under AM 1.5G one sun condition, assuming SRH recombination current density per unit length $J_{A} / d=1000 \mathrm{~A} \mathrm{~cm}^{-2} \mu \mathrm{m}^{-1}$.

recombination current density per unit length $\left(J_{C} / d\right.$ $\left.=1.9 \times 10^{4} \mathrm{~A} \mathrm{~cm}^{-2} \mu \mathrm{m}^{-1}\right)$. When $J_{A} / d$ is lower than $10^{-2} \mathrm{~A} \mathrm{~cm}^{-2} \mu \mathrm{m}^{-1}$, the conversion efficiency shows minimum difference. As $J_{A} / d$ increases, the conversion efficiencies decrease collectively for all structures. These results reveal that SRH recombination plays a key role in degrading the conversion efficiency for InGaN solar cells. Furthermore, Fig. 5(b) illustrates the losses and efficiency map for single junction $\mathrm{In}_{0.15} \mathrm{Ga}_{0.85} \mathrm{~N}$ solar cells in structure $\mathrm{C}$ under $\mathrm{AM}$ $1.5 \mathrm{G}$ one sun condition. For clarity, we plot the losses and efficiency map only to $20 \%$ while transmission loss still dominates in the losses part that is not shown. Both transmission and thermalization losses remain almost constant over all $J_{A} / d$ range at the given structure, while spatial relaxation loss accounts for the degradation of conversion efficiency as $J_{A} / d$ is greater than $0.1 \mathrm{~A} \mathrm{~cm}^{-2} \mu \mathrm{m}^{-1}$. In recombinationrelated mechanisms, SRH recombination is still the primary mechanism, which is consistent with our previous results. This trend could be understood from Equation (1) that large amount of SRH recombination current diminishes the total collected current, thus deteriorating the performance of the solar cell.

By virtue of unique and favorable merits of $\mathrm{InGaN}$ materials, their application and operation for harsh 

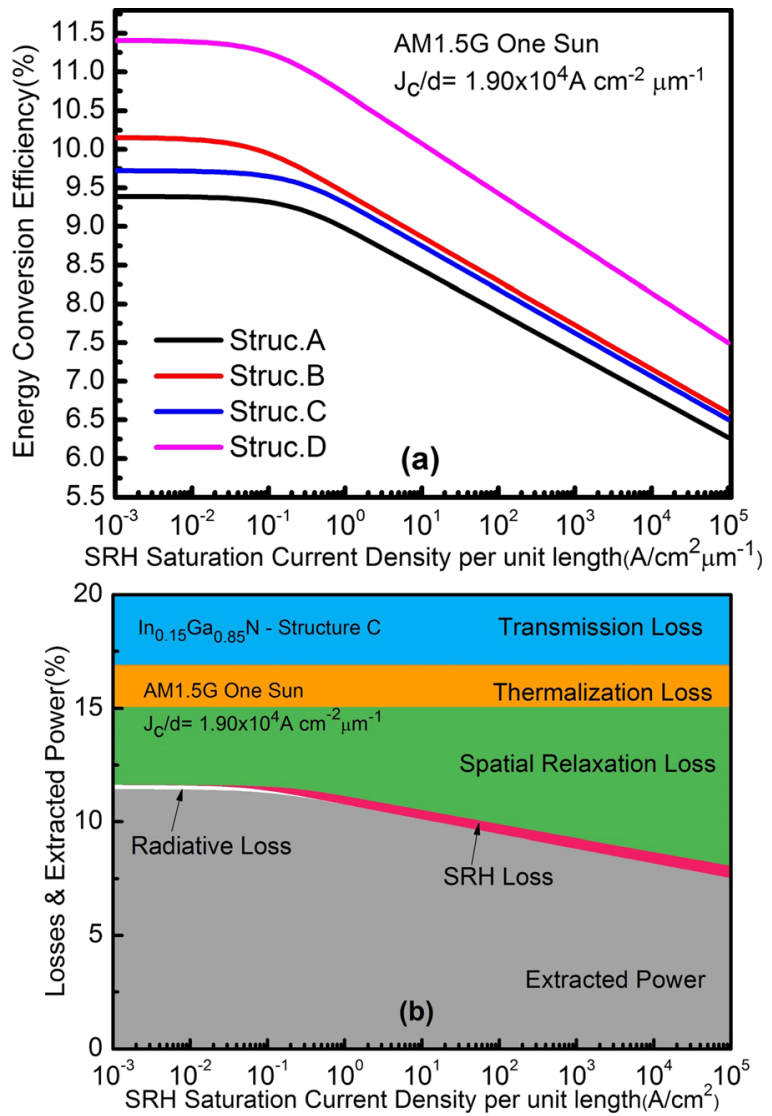

FIG. 5. (a) Energy conversion efficiency vs. SRH recombination current densities per unit length $\left(J_{A} / d\right)$ for single junction $\operatorname{In}_{0.15} \mathrm{Ga}_{0.85} \mathrm{~N}$ solar cells in four structures; (b) losses and extracted power vs. SRH recombination current densities per unit length $\left(J_{A} / d\right)$ for single junction $\operatorname{In}_{0.15} \mathrm{Ga}_{0.85} \mathrm{~N}$ solar cell under AM 1.5G one sun condition in structure $C$, at the optimal junction thickness, with typical Auger recombination current density per unit length $J_{C} / d=1.9 \times 10^{4} \mathrm{~A} \mathrm{~cm}^{-2} \mu \mathrm{m}^{-1}$.

environment like space exploration are desirable and growing solar concentration turns out to be a potent and practical approach to achieve high conversion efficiency. Figure 6(a) presents energy conversion efficiency vs. solar concentrations for single junction $\mathrm{In}_{0.15} \mathrm{Ga}_{0.85} \mathrm{~N}$ solar cells in four structures under AM 1.5G solar spectrum. The efficiencies of all four types of solar cell structures increase linearly with growing solar concentrations, where structure D has the highest efficiency. Note that in practical devices, the energy conversion efficiency will saturate due to the fact that the series resistance and other losses change with solar concentration, which are not considered in our model. Figure 6(b) presents the losses and efficiency maps vs. solar concentration for single junction $\operatorname{In}_{0.15} \mathrm{Ga}_{0.85} \mathrm{~N}$ solar cells in structure $\mathrm{C}$, with typical $J_{A} / d=1000 \mathrm{~A} \mathrm{~cm}^{-2} \mu \mathrm{m}^{-1}$ and $J_{C} / d=1.9 \times 10^{4} \mathrm{Acm}^{-2} \mu \mathrm{m}^{-1}$. The transmission loss still dominates over other loss mechanisms as a result of large bandgap of III-nitrides and there is minimum variation of transmission and thermalization losses with the specified structure. Moreover, spatial relaxation loss gradually drops as rising solar concentrations, which could be ascribed to the fact that the extractable energy of photogenerated carriers is enhanced with the solar concentration. It is noticeable that SRH recombination loss dominates over other recombination-related loss mechanisms throughout
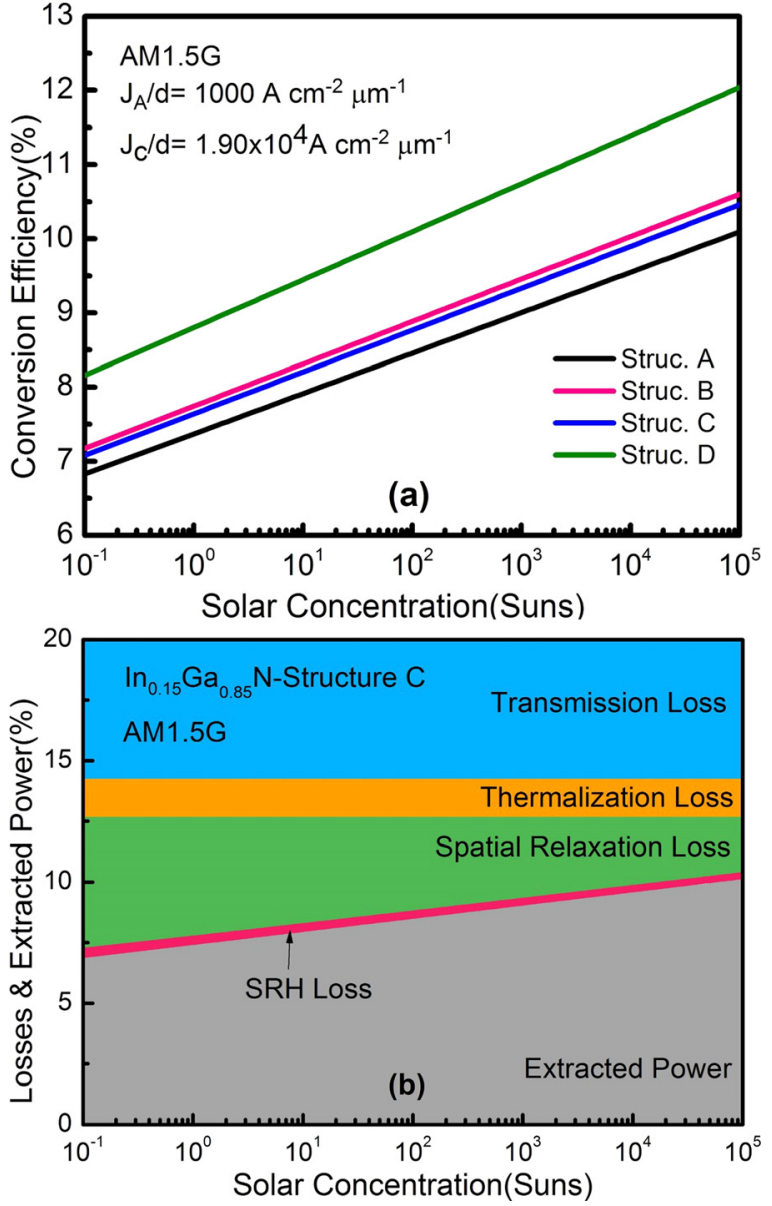

FIG. 6. (a) Energy conversion efficiency vs. solar concentration for single junction $\mathrm{In}_{0.15} \mathrm{Ga}_{0.85} \mathrm{~N}$ solar cells in four structures; (b) losses and extracted power vs. solar concentration for single junction $\mathrm{In}_{0.15} \mathrm{Ga}_{0.85} \mathrm{~N}$ solar cell under AM 1.5G one sun condition in structure $\mathrm{C}$, at the optimal junction thickness, with typical SRH recombination current density per unit length $J_{A} / d=1000 \mathrm{~A} \mathrm{~cm}^{-2} \mu \mathrm{m}^{-1}$ and Auger recombination current density per unit length $J_{C} / d=1.9 \times 10^{4} \mathrm{~A} \mathrm{~cm}^{-2} \mu \mathrm{m}^{-1}$.

the entire range of solar concentration. For GaAs solar cells, the radiative loss would take the lead after 500 suns. $^{7}$ This difference may be attributed to the large amount of subband transition induced from unavoidable defect states during the growth of InGaN materials.

\section{LOSS ANALYSIS OF TWO JUNCTION SOLAR CELLS}

The large tunable direct bandgaps from InGaN material systems offer a unique and promising opportunity to design high-performance multi-junction (MJ) solar cells using a single ternary alloy system. In this section, we focus on the two-junction (2J) InGaN solar cells, which include two junctions in structure A. The loss analysis of $2 \mathrm{~J}$ solar cell is based upon the typical material parameters and properties of InGaN. It is assumed in the model that the Urbach tail energy is $50 \mathrm{meV}$, the effective absorptance of $\overline{A_{\alpha}}=1$, SRH recombination current density of $J_{A}=1900 \mathrm{~A} \mathrm{~cm}^{-2}$, and Auger recombination current density of $J_{C}=3.8 \times 10^{4} \mathrm{~A} \mathrm{~cm}^{-2}$, which are proper up-to-date values of InGaN materials. The equations of SRH recombination current densities $\left(J_{A}\right)$ and Auger recombination current density $\left(J_{C} / d\right)$ and the 
corresponding coefficients are based on Ref. 6. Figure 7 shows (a) bandgap energy and conversion efficiency vs. top-junction bandgap energy and (b) losses and extracted solar power vs. top-junction bandgap energy for $2 \mathrm{~J}$ InGaN solar cells. The top junction bandgap window in Figs. 7(a) and 7(b) is very limited, which could be partly attributed to the perfect current matching condition assumed in the calculation. This was also found in the calculation of three- and four-junction $\mathrm{InGaN}$ solar cells (data not shown here), which could be a potential challenge for the design of MJ InGaN solar cells. With the top-junction bandgap varying from $1.68 \mathrm{eV}$ to $1.82 \mathrm{eV}$, we can observe an efficiency of $43.5 \%$ under AM1.5G one sun radiation. The losses and efficiency map for 2J InGaN solar cells in Fig. 7(b) show that the transmission loss is no longer the major loss mechanism, while the spatial relaxation loss mainly accounts for the degradation of conversion efficiency, especially when the top junction bandgap exceeds $1.78 \mathrm{eV}$. These results indicate that 2- and multi-junction solar cells will reduce the transmission loss and enhance the conversion efficiency compared to $1 \mathrm{~J}$ structure. The drop of loss and extracted power at $1.78 \mathrm{eV}$ may be attributed to the atmospheric features of AM $1.5 \mathrm{G}$ solar spectrum. Therefore, decreasing spatial relaxation loss will become a critical issue for the design of $2 \mathrm{~J} \mathrm{InGaN}$ solar cells. Meanwhile, SRH loss still dominates in the recombination-related losses, which is again due to the material quality of the $\mathrm{InGaN}$ active layers.
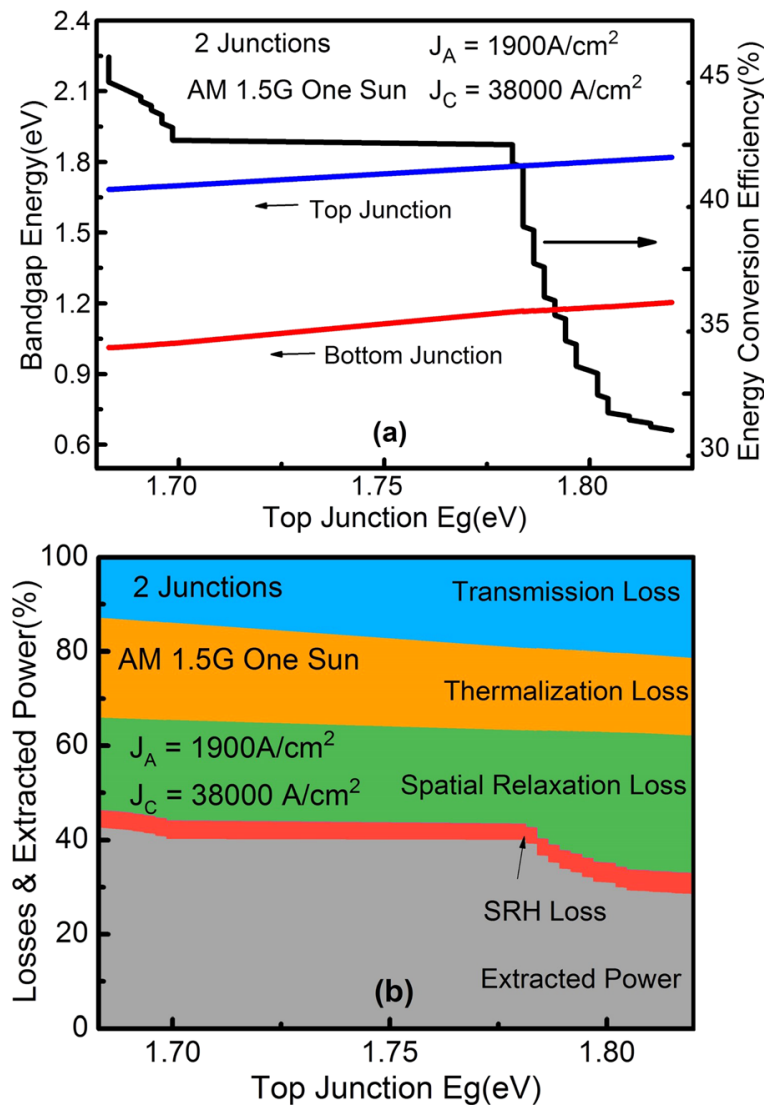

FIG. 7. (a) Bandgap energy and conversion efficiency vs. top-junction bandgap energy and (b) losses and extracted solar power vs. top-junction bandgap energy for $2 \mathrm{~J} \mathrm{InGaN} \mathrm{solar} \mathrm{cells,} \mathrm{with} \mathrm{SRH} \mathrm{recombination} \mathrm{current}$ density $J_{A}=1900 \mathrm{~A} \mathrm{~cm}^{-2}$ and Auger recombination current density $J_{C}=3.8 \times 10^{4} \mathrm{~A} \mathrm{~cm}^{-2}$.
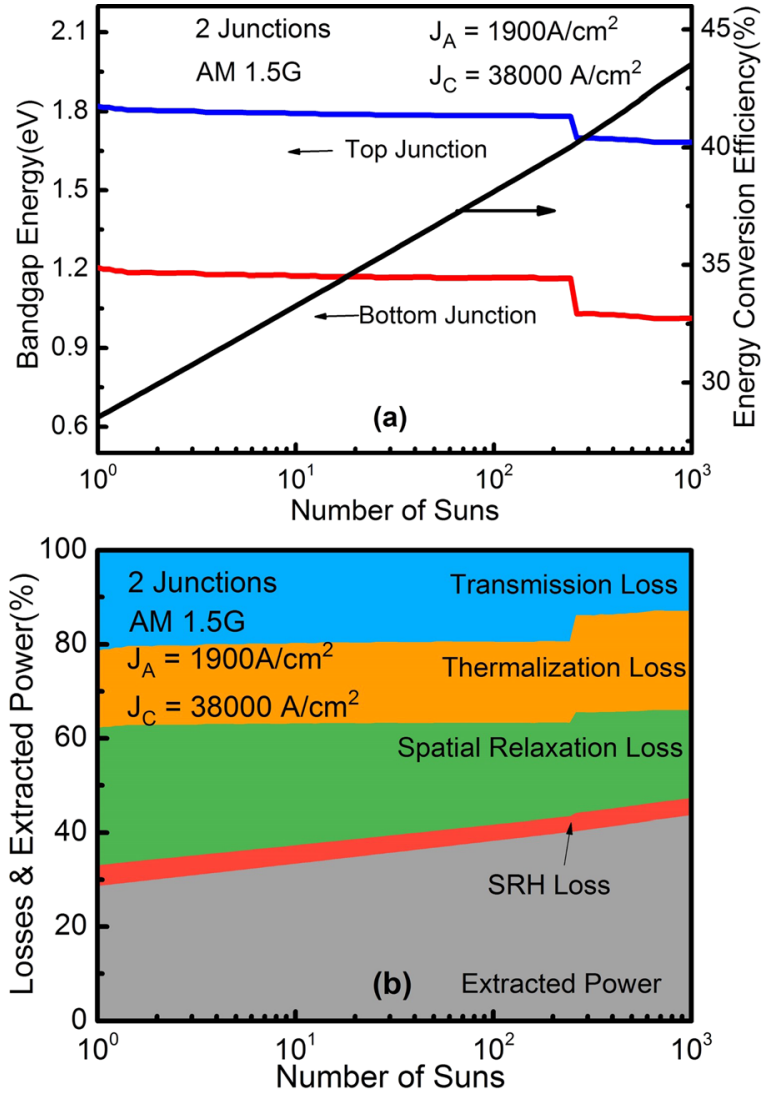

FIG. 8. (a) Bandgap energy and conversion efficiency vs. solar concentration and (b) losses and extracted solar power vs. solar concentration for $2 \mathrm{~J} \mathrm{InGaN}$ solar cells, with SRH recombination current density $J_{A}=1900 \mathrm{~A} \mathrm{~cm}^{-2}$ as well as Auger recombination current density $J_{C}=3.8 \times 10^{4} \mathrm{~A} \mathrm{~cm}^{-2}$.

To further investigate the possible PV applications of InGaN materials system, the correlated bandgap energies and maximum energy conversion efficiency are plotted in Fig. 8(a) along with losses and extracted power in Fig. 8(b). Figure 8(a) presents that the optimal bandgap energies of top junction and bottom junction remain almost constant and decrease significantly at 200 suns concentrations, which could allow more photons to be absorbed. While in Fig. 8(b), both transmission loss and spatial relaxation loss reduce collectively and thermalization loss tends to rise, which could be ascribed to the decreasing optimal bandgap energy as growing solar concentrations. Aside from that, SRH loss still takes up the most part of the total recombination losses. Hence, rising solar concentration proves to be an efficient approach for high performance InGaN solar cells, which corresponds to our previous results of single junction InGaN solar cells.

\section{CONCLUSION}

To thoroughly investigate PV performance and loss mechanisms in InGaN solar cells, we apply a semi-analytical model to $1 \mathrm{~J}$ and $2 \mathrm{~J}$ solar cells. By considering photon recycling, spontaneous emission, non-radiative recombination losses, and non-step like absorptance and emittance, we explore four types of fundamental loss mechanisms with typical published material parameters. We determine that the width of Urbach energy has a significant effect on the 
emittance of surfaces, which is broad compared to other III$\mathrm{V}$ materials and is not negligible in the whole solar spectrum. This below-bandgap tail boosts the light absorption, resulting in increasing the short-circuit current and reducing the opencircuit voltage. ${ }^{7}$

Furthermore, we also investigate the roles of SRH recombination current densities per unit length and sun concentration for four structures. We identify that the transmission loss is the major cause responsible for loss and $\mathrm{SRH}$ loss is the dominant recombination loss mechanism under any solar concentration. As a result, both improving the material quality of InGaN active layers and rising solar concentration offer constructive ways to enhance the performance of InGaN solar cells. With typical $J_{A} / d$ and $J_{C} / d$ values, the predicted energy conversion efficiency could be $7.6 \%$ for structure C. Moreover, conversion efficiency could be greatly enhanced by increasing solar concentration and the peak efficiency could be achieved as $9.0 \%$ under 1000 suns. As for $2 \mathrm{~J} \mathrm{InGaN} \mathrm{solar} \mathrm{cells,} \mathrm{the} \mathrm{current} \mathrm{matching} \mathrm{issue}$ would lead to the limited choice of top-junction bandgap while the efficiency as high as $43.5 \%$ is achieved with the top-junction bandgap from $1.68 \mathrm{eV}$ to $1.82 \mathrm{eV}$. By analyzing the optical properties and loss mechanisms, these results provide fundamental insights and detailed guidance for the future designs and developments of InGaN solar cells.

\section{ACKNOWLEDGMENTS}

This work was supported by an Early Career Faculty grant from NASA's Space Technology Research Grants Program.

${ }^{1}$ M. A. Green, K. Emery, Y. Hishikawa, W. Warta, and E. D. Dunlop, Prog. Photovoltaics: Res. Appl. 23, 1 (2015).

${ }^{2}$ J. Wu, W. Walukiewicz, K. M. Yu, W. Shan, J. W. A. Iii, E. E. Haller, H. Lu, W. J. Schaff, W. K. Metzger, and S. Kurtz, J. Appl. Phys. 94, 6477 (2003).

${ }^{3}$ O. Jani, I. Ferguson, C. Honsberg, and S. Kurtz, Appl. Phys. Lett. 91, 132117 (2007).

${ }^{4}$ A. G. Bhuiyan, K. Sugita, A. Hashimoto, and A. Yamamoto, IEEE J. Photovoltaics 2, 276 (2012).

${ }^{5}$ N. G. Toledo, D. J. Friedman, R. M. Farrell, E. E. Perl, C.-T. T. Lin, J. E. Bowers, J. S. Speck, and U. K. Mishra, J. Appl. Phys. 111, 054503 (2012).
${ }^{6}$ C. A. M. Fabien, M. Moseley, B. Gunning, W. A. Doolittle, A. M. Fischer, Y. O. Wei, and F. A. Ponce, IEEE J. Photovoltaics 4, 601 (2014).

${ }^{7}$ D. Ding, S. R. Johnson, S.-Q. Yu, S.-N. Wu, and Y.-H. Zhang, J. Appl. Phys. 110, 123104 (2011).

${ }^{8}$ D. Ding, S. R. Johnson, and Y.-H. Zhang, in 2010 35th IEEE Photovoltaic Specialists Conference (PVSC) (IEEE, 2010), pp. 002908-002911.

${ }^{9}$ S. L. Chuang, Physics of Photonic Devices (John Wiley \& Sons, 2012).

${ }^{10}$ S. Liu, D. Ding, S. R. Johnson, and Y.-H. Zhang, Proc. SPIE 8256, 82560M (2012).

${ }^{11}$ R. M. Farrell, C. J. Neufeld, S. C. Cruz, J. R. Lang, M. Iza, S. Keller, S. Nakamura, S. P. DenBaars, U. K. Mishra, and J. S. Speck, Appl. Phys. Lett. 98, 201107 (2011).

${ }^{12}$ E. Matioli, C. Neufeld, M. Iza, S. C. Cruz, A. A. Al-Heji, X. Chen, R. M. Farrell, S. Keller, S. DenBaars, U. Mishra, S. Nakamura, J. Speck, and C. Weisbuch, Appl. Phys. Lett. 98, 021102 (2011).

${ }^{13}$ C. J. Neufeld, S. C. Cruz, R. M. Farrell, M. Iza, S. Keller, S. Nakamura, S. P. DenBaars, J. S. Speck, and U. K. Mishra, Appl. Phys. Lett. 99, 071104 (2011).

${ }^{14}$ J.-K. Sheu, F.-B. Chen, S.-H. Wu, M.-L. Lee, P.-C. Chen, and Y.-H. Yeh, Opt. Express 22, A1222 (2014).

${ }^{15} \mathrm{~S}$. Adachi, Properties of Semiconductor Alloys: Group-IV, III-V and II-VI Semiconductors, Wiley Series in Materials for Electronic \& Optoelectronic Applications (Wiley, Chichester, UK, 2009).

${ }^{16}$ M. M. Leung, A. B. Djurisisić, and E. H. Li, J. Appl. Phys. 84, 6312 (1998).

${ }^{17}$ R. W. Martin, P. G. Middleton, K. P. O’Donnell, and W. Van der Stricht, Appl. Phys. Lett. 74, 263 (1999).

${ }^{18}$ M. Yamada, T. Mitani, Y. Narukawa, S. Shioji, I. Niki, S. Sonobe, K. Deguchi, M. Sano, and T. Mukai, Jpn. J. Appl. Phys. Part 2-Lett. Express Lett. 41, L1431 (2002).

${ }^{19}$ D. S. Wuu, W. K. Wang, K. S. Wen, S. C. Huang, S. H. Lin, S. Y. Huang, C. F. Lin, and R. H. Horng, Appl. Phys. Lett. 89, 161105 (2006).

${ }^{20}$ H. Gao, F. Yan, Y. Zhang, J. Li, Y. Zeng, and G. Wang, J. Appl. Phys. 103, 014314 (2008).

${ }^{21}$ H. Chen, H. Guo, P. Zhang, X. Zhang, H. Liu, S. Wang, and Y. Cui, Appl. Phys Express 6, 022101 (2013).

${ }^{22}$ H. Lee, M. Jue, H. Yoon, S. Lee, and C. Kim, Appl. Phys. Lett. 104, 182105 (2014).

${ }^{23}$ L. J.-H. Lin and Y.-P. Chiou, Opt. Express 23, A614 (2015).

${ }^{24}$ M. Beaudoin, A. J. G. DeVries, S. R. Johnson, H. Laman, and T. Tiedje, Appl. Phys. Lett. 70, 3540 (1997).

${ }^{25}$ C. H. Grein and S. John, Phys. Rev. B 39, 1140 (1989).

${ }^{26}$ F. Meillaud, A. Shah, C. Droz, E. Vallat-Sauvain, and C. Miazza, Sol. Energy Mater. Sol. Cells 90, 2952 (2006).

${ }^{27}$ C. H. Qiu, C. Hoggatt, W. Melton, M. W. Leksono, and J. I. Pankove, Appl. Phys. Lett. 66, 2712 (1995).

${ }^{28}$ A. Cremades, L. Görgens, O. Ambacher, M. Stutzmann, and F. Scholz, Phys. Rev. B 61, 2812 (2000).

${ }^{29}$ S. Chichibu, T. Mizutani, T. Shioda, H. Nakanishi, T. Deguchi, T. Azuhata, T. Sota, and S. Nakamura, Appl. Phys. Lett. 70, 3440 (1997). 